\title{
Using mobile technologies for social media based library services at the University of Development Studies Library, Ghana
}

\author{
Mirriam Akeriwa \\ University of Development \\ Studies LibraryTamale, Ghana. \\ Email: makeriwe@yahoo.com
}

\author{
Cecilia Penzhorn \\ Department of Information \\ Science, University of Pretoria, \\ Pretoria, South Africa. Email: \\ cecilia.penzhorn@up.ac.za
}

\author{
Marlene Holmner \\ Department of Information \\ Science, University of Pretoria, \\ Pretoria South Africa. Email: \\ marlene.holmner@up.ac.za
}

\begin{abstract}
Libraries all over the world are utilizing the latest Information and Communication Technologies to assist in their objective of providing clients with effective and efficient services, as well as timely access to needed information. The implementation of social media and the use of mobile technologies for service delivery are trends that have, however, not yet been fully embraced by academic libraries in developing countries in sub-Saharan Africa. This article reports on a study aimed at investigating the possibility of using mobile technologies to implement social media based services to graduate students at the University for Development Studies Library in Ghana. This article provides a short overview of the various technologies and services available, discusses the opportunities and challenges for implementing such services at the University Library, and provides a number of recommendations to support this goal.
\end{abstract}

\section{Introduction}

The use of social media has become an integral part of our everyday lives. Furthermorethe influence of these technologies on the learning habits of students and their approach to acquiring information is experienced by educators on a daily basis (Mason and Rennie, 2008). Research and scholarly communications have become social practices due to collaborative processes and knowledge being documented and passed around via social media (Cann, Konstantia and Hooley, 2011). In the same vein mobile technologies, and particularly smartphones, are "driving significant behaviour changes in both consumers and employees" (Jones, 2011) and therefore also have a significant impact on students and researchers everyday behaviour.

Universities recognise the need to adapt to these changing environments and their associated demands and expectations in order to fulfil the information needs of students and researchers and help them succeed in their academic endeavours (Tess, 2013; Wentzel et al., 2005). Academic libraries, as an essential part of academe, need to actively address the many challenges for the design and delivery of innovative resources and services in order to stay relevant (Lippincott, 2010; Bell, 2012). Libraries world-wide are therefore increasingly adopting a variety of social technologies and mobile platforms/interfaces and applications in order to deliver more effective and accessible services to their clients.

The university library has always been regarded as the 'heart' of the learning community, providing a place and the resources for students and faculty to do their research and advance their knowledge (Simmonds, 2001). Thus, there is an undisputed need for libraries in developing countries to be on the same level with technological advances as the rest of the library world. However, the implementation of social media and the use of mobile communication for service delivery are trends that are yet to be fully embraced by academic libraries in sub-Saharan Africa and other places in the developing world (Chisenga, 2012; Makori, 2012). University 
libraries in Ghana, in particular, are trailing behind in this respect. Many of these institutions still operate mainly as 'traditional' libraries where key library functions are carried out manually, which has a considerable negative impact on efficient and effective client services.

It is within this context that a study, discussed in this article, was undertaken to investigate the feasibility of using mobile technologies to implement social media based services to improve service delivery at the University for Development Studies (UDS) Library in Ghana. Furthermore, it discusses research undertaken and its outcomes The article concludes with recommendations regarding the use of mobile technologies for the implementation of social media services in the UDS Library.

\section{Practical application of social media and mobile technologies in academic libraries}

University libraries are expected to provide timely access to relevant information in order to meet the needs of academics and researchers. One of the main requirements in this regard is that institutions match these information requirements with the technology-specific needs and demands of clients (Makori, 2012). The use of social media applications and mobile devices are two of the latest technologies that academic libraries are leveraging to enhance their overall service delivery.

Adapting services to fit with the social networking environment where personal interaction occurs between people with common interests would, to a great extent, be merely logical extensions of what librarians have been doing all along, as libraries have always been about services and personal relationships with their clients (ACRL, 2007). The use of social media in libraries is growing fast as these tools offer a wealth of opportunities for the design and delivery of a variety of new resources and services in the academic library (Penzhorn and Pienaar, 2009; Mahmood and Richardson, 2011). Some of the more frequently used social media tools are as follows:

- Blogs are among the most often employed applications in academic libraries. Many blogs contain current scholarly opinions and are becoming a valid source of information used by lecturers and researchers to get the latest ideas, for example, about particular subjects and research interests (Alexander, 2008). Libraries can therefore create blogs for specific subjects to keep users updated on their areas of interest and also provide information on new Internet sources. Blogs are also used to disseminate library news, informing the clients of library activities, and even publishing the library newsletter (Chua and Goh, 2010; Harinarayana and Raju, 2010). Academic libraries also use blogs to promote and market their services (Mahmood and Richardson, 2011).

RSS (Really Simple Syndication) is an excellent tool for obtaining information on a regular basis from news services, blogs and relevant content from databases. Some of its most common uses among academic libraries are to include the dissemination of library news, for library announcements, the exhibition of new and already existing acquisitions, as well as for reference services (Chua and Goh, 2010; Mahmood and Richardson, 2011). 
- $\quad$ Social bookmarking / user tagging can be used to link users to free bookmarking sites online and also presents many opportunities for networking with other persons or scholars with similar interests. Academic libraries utilize this facility to connect their clients to online bookmarking sites, which are specifically related to their subject areas. These sites also allow clients to create their own tags (keywords) for content that they like, as well as sharing items they find useful in the library's online catalogue (Harinarayana and Raju. 2010; Mahmood and Richardson, 2011).

- Wikis are used in academic libraries inter alia to develop subject guides and archive past reference questions or queries on library services. Wikis are also used for promoting and managing internally produced resources such as committee minutes, procedures, rules, policies and so forth (Chua and Goh, 2010; Harinarayana and Raju, 2010; Mahmood and Richardson, 2011).

- $\quad$ Social Networking Sites (SNS) such as Facebook, MySpace, YouTube and Flickr are used by academic libraries for general sharing of information, marketing their services, and creating image databases to share their photos, videos, PowerPoint presentations, among others (Harinarayana and Raju , 2010; Mahmood and Richardson, 2011).

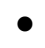

Subject librarians can also utilize professional Social Networking sites such as LinkedIn, Researchgate, Academia.edu and so forth for professional networking and communication with clients and thereby create their own professional identities within the academic environment.

- Podcasts are applications that can enhance information dissemination, for example, to deliver information on library services and to give tutorials to clients on the use of library resources such as the library catalogue (Harinarayana and Raju, 2010).

- Instant Messaging (IM) are applications that allow for real time communication. Many academic libraries use IM to enhance their reference service delivery processes because they allow them to respond instantly to enquiries from their clients (Chua and Goh, 2010; Harinarayana and Raju, 2010).

Mobile communication is claimed to be the only technology to ever be accepted by and become accessible to such vast numbers of people, both in developed and developing countries, in a very short time (Castells, 2007; UNDP, 2012). Moreover, the use of these devices has become part of the daily lives of most students of higher education (Choy, 2010). Therefore, it is self-evident that many academic libraries are designing services around mobile technologies in order to meet the changing needs of their clients (Lippincott, 2010; Vila, Galvez and Campos, 2010). Some of the ways in which this has been accomplished are the following:

- Mobile interfaces and online public catalogues. Libraries are developing mobile versions of their websites to provide their clients with on-the-go access to their services, catalogues, collections, subject guides, e-journals and library hours (Murray, 2010; Vila, Galvez and Campos, 2010).

- Mobile collections and databases. Database publishers are increasingly introducing mobile versions of their databases to ensure clients can access their e-books and e-journals through their mobile devices (Lippincott, 2010). Therefore, libraries are also providing mobile access to their digital media 
collections which makes it possible for clients to benefit from library services remotely (Murray, 2010).

- Another example of this type of access is Google Books (via Google mobile) which can be linked to the library's online catalogue enabling direct access to abstracts and full text of books of interest to the clients through their mobile devices (Kroski, 2008; Murray, 2010).

- Mobile reference services is another facility which libraries are implementing to enhance services. Reference queries can be sent by Short Message Service (SMS), e-mail, Instant Messaging, or audio or video chat to a reference librarian, and the response is given through the same means (Kroski, 2008; Lippincott, 2010). Although not all reference questions can be handled in this manner, mobile reference services would enable not only the expansion of the library's service points and outreach prospects but also have the additional benefit of enabling synchronous reference transactions in a fast and convenient way (Vila, Galvez and Campos, 2010).

- Mobile instruction and mobile tours of the library. Instruction services such as library orientation, information literacy and other awareness programs are services that libraries are also providing by means of mobile devices. For example, libraries are able to use YouTube to provide library tours to clients and use podcasts to afford distance users access to library content (Murray, 2010). Services such as "self-service" library instructions (Murray, 2010) and "Guide by call" services (Kroski, 2008) are other packages that increase and thus add value to existing services.

- Short Message Service (SMS) is also being used by libraries to provide speedy notifications to their clients. With the use of the SMS notification system libraries provide their clients with access to quick news announcements and fast responses to general queries (Luo and Bell, 2010).

\section{Background to the study}

The University for Development Studies (UDS) was founded in 1992. It is one of six public universities in Ghana and also one of the youngest in the country. The University was established with the aim of combining academic studies with practical field training. This aim is achieved through the three-term trimester system that the University operates with: the first two trimesters are dedicated to classroom study and the third trimester is dedicated to practical field-programmes. The students are sent to the local communities to live there and to study development issues in these communities.

UDS runs a multi-campus system with campuses located in three of the ten administrative regions of Ghana, namely: the Upper East, Upper West and Northern Regions. All three UDS campuses offer both undergraduate and graduate courses. Graduate programmes include MA, MSC, MPhil and $\mathrm{PhD}$ and are offered on a regular, as well as a "sandwich" basis. Sandwich programmes are run only during vacations, i.e. between semesters of the regular academic programmes.

Each of the three campuses has a library which serves the information needs of its specific clients. Although efforts have been made to automate the cataloguing, circulation and reference services, most of the library operations are still performed 
manually. However, none of the automated functions is online yet, which means that library resources cannot be accessed from off-campus; students have access to only those resources physically available in their various campus libraries. Graduate students, who spend very little or no time on campus, are therefore particularly challenged in their information seeking and research efforts.

The social media environment offers a number of advantages for both experienced and new researchers. For example, it increases awareness of and between fellowresearchers as more and more well-known researchers maintain professional blogs and other similar online spaces. Researchers can get quick feedback on their work from colleagues around the world; and collective knowledge is documented and passed down through various collaborative ventures (Cann, Konstantia and Hooley, 2011; Farrell, 2012).

The role of the academic library is to support the academic activities of the staff and students of its university as a whole, providing services geared towards their research and scholarship needs. Therefore, libraries should use the various social media tools, not only to support researchers in their "normal" information seeking activities, but also to assist them to identify research partners, collaborate on research information, disseminate research results, write research reports, and so forth (Adolphus, 2011). The need for libraries in Africa to develop institutional initiatives or strategies for the implementation and use of social media has become particularly crucial (Chisenga, 2012).

Ghana has the highest mobile broadband penetration in Africa with the latest reports showing that mobile penetration has exceeded 100\% (Ghana MMA, 2013). In the light of information obtained in the literature and the current world-wide trends in this regard, it becomes apparent that the solution to the problem of (remote) information access and services as discussed above, and subsequently meeting the information needs of many of the UDS library's clients, could lie in the provision of social media based mobile library services.

\section{Conducting the study}

\section{Target population and sampling}

The target group for this study consisted of students pursuing any of the graduate programmes at the Graduate School at UDS Tamale Campus. The Tamale Graduate School is the main campus for graduate studies, offering the majority of graduate courses and thus it has the most graduate students. As such, it serves as the best representation of the total graduate student population of the University for Development Studies.

Choosing graduate students for this study was considered an obvious and logical decision as most of these students work full-time and going to the library to find their needed information can sometimes be a daunting task. One can also assume that as they have successfully completed their undergraduate programs, they would be more experienced in using library resources than undergraduate students and therefore more likely to offer meaningful feedback on which library services should go mobile and which social media applications would better serve their information needs. 
After obtaining a complete list of students from the Graduate School registry a table by Sarantakos (2005), adopted from Krejcie and Morgan (1970), was used to determine the sample size. Krejcie \& Morgan constructed this table using the formula developed by a division of the National Education Association in the USA (Powell \& Connaway, 2004). The table "calculates" sample sizes based on ranges of population sizes. Accordingly, the sample for this study came to 155 out of the total of 256 graduate students based at the Tamale Campus Graduate School.

\section{Data collection}

A questionnaire was deemed as the most appropriate data collection instrument for this study. One of the core advantages for the purposes of this study was the fact that questionnaires offer respondents the flexibility of when to complete them. This was convenient as the participants were students who have very little time to spare when they come to campus, making it difficult in some cases to get them to complete the questionnaire immediately on receiving it. The questionnaire was thus distributed to the respondents who were then given the choice of either completing it immediately or at a later more expedient time.

The first part of the questionnaire consisted of a set of questions aimed at finding out whether respondents use social media applications, which ones are used and how often, and whether they thought the implementation of social media tools for use in the library would be feasible. This was followed by questions focused on learning about respondents' ownership of mobile devices and access to the Internet by means of these devices, whether they thought it could be useful to access library services through their mobile devices, as well as the type of mobile library services that they thought could be provided. The questionnaire consisted of both open-ended and closed-ended questions, eliciting both qualitative and quantitative data.

\section{Data analysis and interpretation}

For the analysis of qualitative data generated by the open-ended questions, coding principles were used to organise the responses into categories that identified and brought together corresponding themes (Berg, 1998). The quantitative data was analysed using inferential statistics which was particularly suitable for use in this study. The Statistical Package for the Social Sciences (SPSS) was employed to analyse this data.

The data interpretation was done by using the analysed data in conjunction with information found in the literature, as well as the researcher's background knowledge of the study area. All of the analysed questions (both closed and open ended) were considered and an interpretation provided for each of them by way of discussions to support or expound on the findings.

\section{Outcomes of the research}

Analysis of the data obtained from the 119 respondents (out of the 155) who completed the questionnaires, showed the following: 
- The majority of the respondents $(89 \%)$ indicated that they do use social media applications with $11 \%$ answering in the negative.

- The applications used most often by respondents were social networking (99\%), instant messaging (62\%) and video sharing (61\%). The numbers of respondents using other tools were considerably lower, with only $39 \%$, for example, using blogs and $16 \%$ of the respondents indicating that they use social bookmarking (see Figure 1).



Figure 1. Types of social media applications used by respondents.

- $89 \%$ of the above-mentioned respondents who make use of social media showed that they use social networking applications (such as Facebook) on a daily basis with only $30 \%$ indicating that they use instant messaging every day. None of the other applications was used on a daily basis (see Figure 2). In the same vein respondents indicated that they were most proficient in the use of social networking tools but very few regarded themselves as having "excellent" abilities in the use of any of the tools (as indicated in Figure 3). 


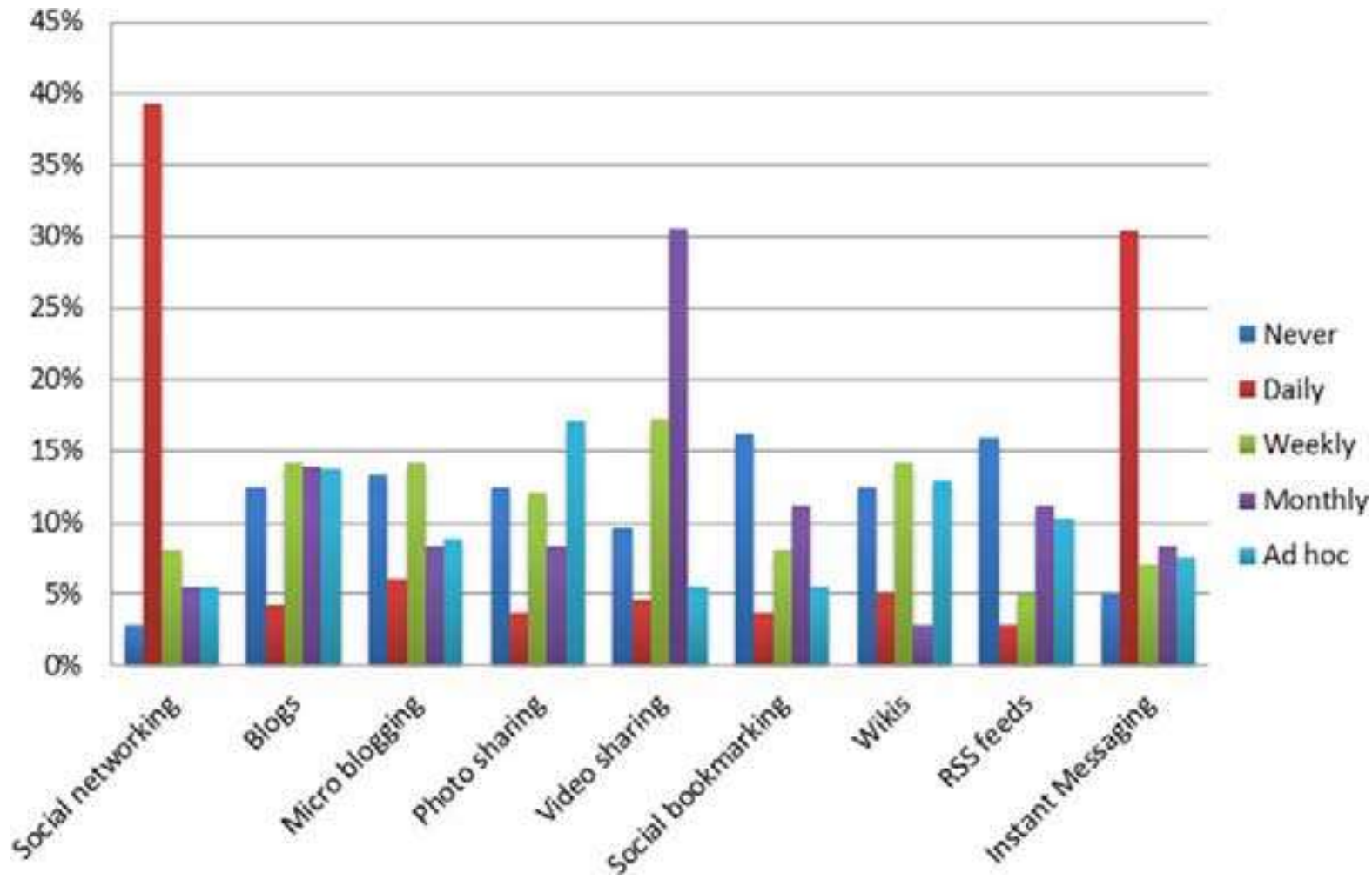

Figure 2. Frequency of use of social media applications.



Figure 3. Users' ability in using social media applications.

- The majority of the respondents (94\%) stated that social media should be applied for library services; with instant messaging, social networking and social bookmarking regarded as being potentially the most useful applications for such use (see Figure 4). 


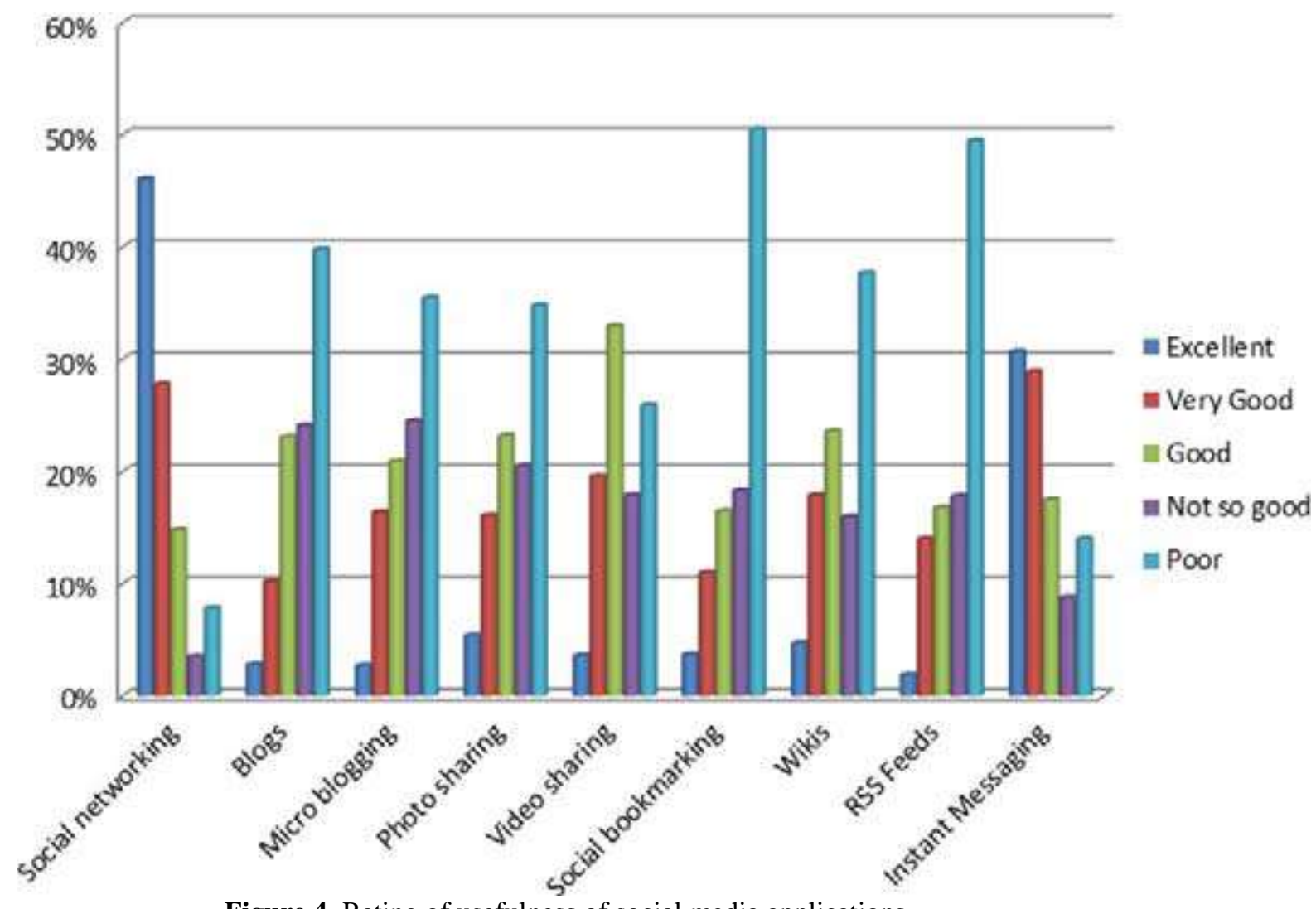

Figure 4. Rating of usefulness of social media applications.

- All of the respondents own a mobile device, with 117 of the total of 119 indicating that they own a mobile phone. Laptop ownership amounted to 37\%, whilst only $6 \%$ of the respondents own iPads. Ownership of PDAs and eBook readers came to less than $1 \%$. (see Figure 5).

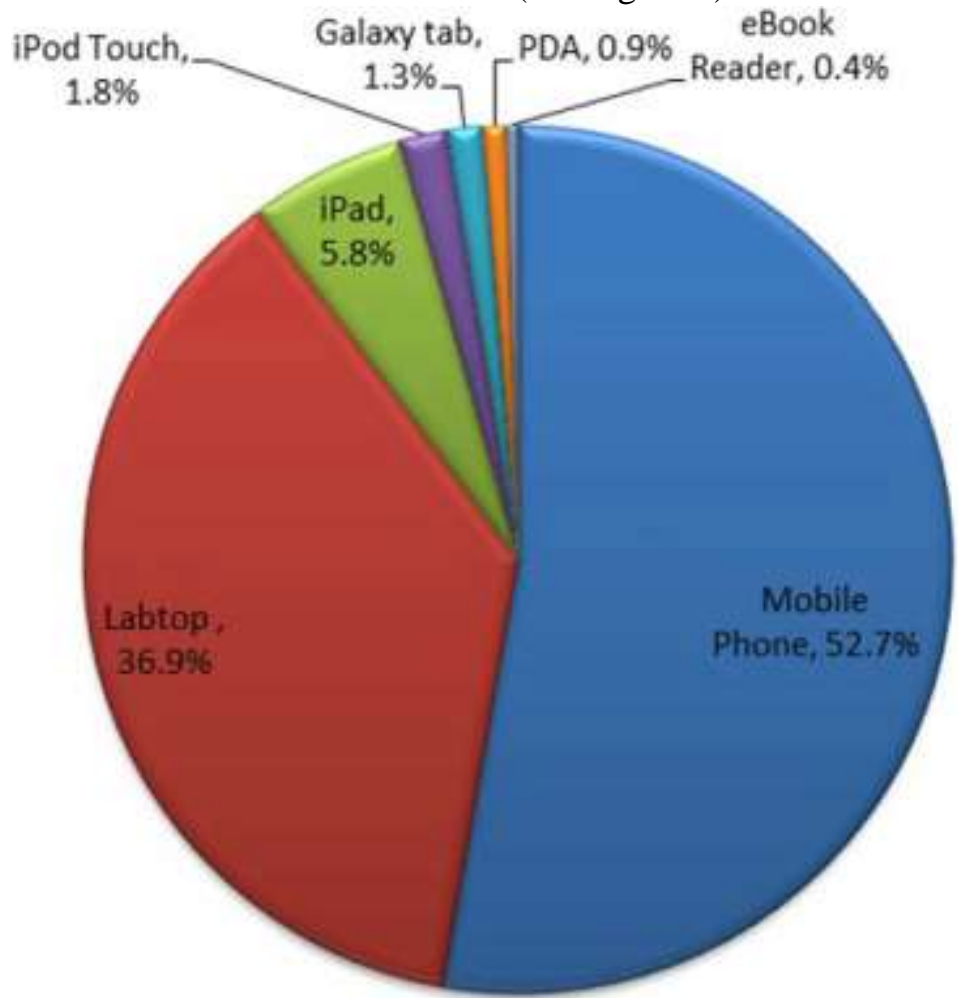

Figure 5. Diagram showing mobile device ownership of respondents. 
- The number of respondents who are able to access the Internet by means of their mobile devices amounted to $90 \%$.

- Respondents indicated that they used their mobile phones for a wide variety of purposes (apart from the 100\% who said that they make or receive phone calls). These functions included text messaging (98\%), listening to the radio (81\%), taking photographs $(76 \%)$, surfing the Net (76\%), send/receive emails (66\%), playing games (61\%), viewing maps (44\%) and recording video clips (41\%).

- With regards to the usefulness of (future) mobile library services, $95 \%$ of the respondents indicated that they would like to access the library through their mobile devices with the majority of this group (92\%) specifying that they would like reference services to be provided in this way. Other possible services on the respondents' wishlists were: access to e-resources (81\%), providing library news (75\%), being able to search the OPAC (74\%), provision of circulation services $(72 \%)$ and access to subject guides (60\%). (as shown in Figure 6).

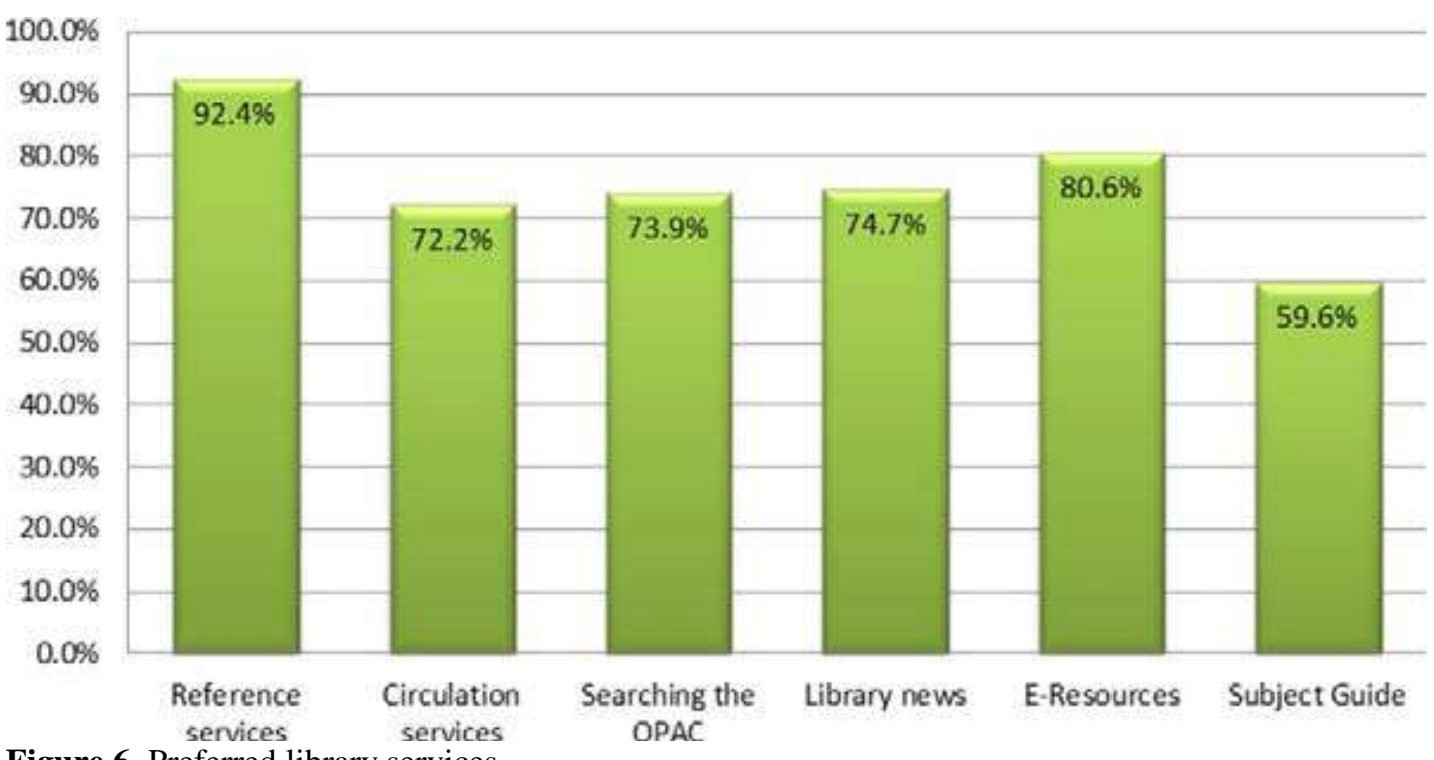

Figure 6. Preferred library services.

\section{Discussion of the findings}

\section{General use of social media}

In order to ascertain the familiarity of the respondents with social media in general, they were requested to indicate their use or non-use of the various applications, and also how often they used them. If respondents revealed that they did not use the tools, they were asked to provide a reason / reasons for this.

With a view to the future implementation of social media in the library, the overall high usage rate by the respondents is encouraging. Their indication of using social media regularly could, for example, provide the ideal opportunity for the UDS Library to introduce this as an active tool for sharing information on many levels amongst its clients. Even though some of the tools generally used for enhanced library services such as blogs, wikis and social bookmarking were not on the respondents' list of often-used applications, it was encouraging to see their use of a number of other applications not mentioned on the questionnaire such as Dropbox, Skype, WhatsApp, which suggests their familiarity with social media practices in general. 
The reason that respondents gave for not using social media personally was mainly indicated as "not having the ability to use them" This should not be seen as a drawback but as an opportunity for the library to introduce the few non-users to these applications and also to inform them of and practically demonstrate the benefits they stand to gain from using them.

\section{Use of social media in the library}

Respondents were asked to rate the possible usefulness of various social media applications for service provision in the University library and to indicate which of these tools could be put to the best practical use. The overall high ratings given by the respondents can be attributed to the fact that respondents who use social media in their everyday life would be cognisant with the possible benefits for professional and academic use as well. The types of tools that were regarded as feasible for library service provision, such as social networking and instant messaging, corresponded broadly to those used by the respondents in everyday life.

Although the majority of the respondents were of the opinion that social media services would be very useful in the library, it was interesting to note the reasons provided by the $6 \%$ who indicated that it would not be possible and therefore of no use to introduce social media in the library. The fact that there is currently either very limited, slow or virtually no Internet connectivity (a country-wide phenomenon and thus manifested in the library as well) was the main explanation provided for this point of view. Respondents also seemed to have some knowledge of the lack of sufficient resources in the library and listed this as a further reason for their negative response regarding the possible implementation of such a project. These are all issues that the library is well aware of and would need to address in the future.

A further "throw-away" i.e. check question was asked of respondents, namely whether the UDS Library currently uses social media for delivering services or not, to which $15 \%$ of the respondents replied affirmatively. It is a known fact that the library definitely has not yet implemented any such services or tools. It could be that the respondents responsible for this answer are ignorant of or not interested in the specific details of services provided by the library. On the other hand, users who do not know what social media constituted, may have misconstrued some of the general e-resources which they access in the library to be social media sources/services.

\section{Use of mobile devices}

Respondents were asked to indicate whether or not they owned a mobile device, the type of device they owned and whether their mobile devices provide Internet access. It was also deemed necessary to ascertain whether respondents used their mobile devices to access social media applications specifically.

Nearly all of the respondents own at least one (or more) mobile device with Internet capabilities, and they use them for a wide variety of purposes, including the use of social media. The affirmation of ownership and actual use of such an Internet enabled tool is essential if the UDS Library plans to deliver some of its services by means of mobile technologies. 


\section{Usefulness of accessing library services through mobile devices}

Respondents' views were sought to determine the usefulness of accessing the library's services through their mobile devices. A great deal of enthusiasm was expressed in this regard suggesting that, with the necessary infrastructure and technical expertise, there exists a real possibility of delivering library services through mobile devices to graduate students at UDS.

\section{General comments}

To ensure that respondents could also present their own opinions on the subject matter, open-ended questions were included throughout the questionnaire and an opportunity for general comments was provided as a conclusion to the questionnaire.

The most common sentiment expressed by the respondents was the hope that social media services will actually be implemented by the library. It was felt that if such services are introduced, this would facilitate easy access to the library's resources, enhance teaching and learning for graduate students, and generally improve information dissemination and other similar services. These comments correspond with what is generally found in the literature regarding the advantages of implementing social media for improved library services. These applications are easy to use, people feel comfortable using them and the open nature of the applications make them very useful in the teaching and learning environment.

The possible high costs of implementing such a project was the only issue that respondents felt could present a barrier to successful execution; which is something that needs to be looked into by the library.

\section{The way forward}

The ways in which people communicate, acquire, and share knowledge will inevitably affect the academic library. The widespread adoption of mobile technologies coupled with the increasing use of social media tools on a daily basis has impacted on libraries in many ways. On the one hand students have turned to accessing electronic sources so readily available online, something which has in many instances thrown the academic library into a state of instability (Lippincott, 2010). On the other hand these circumstances create numerous opportunities for the development of alternative means of providing improved and innovative services.

Mobile devices have proved to be convenient and practical in terms of mobility and ease of access to information anywhere, any time (Hey, 2007). In addition, using social media, people are able to collaborate and share content over a wide spectrum of fields ranging from the personal to the professional. It lies in the hands of the library to take advantage of the vast range of opportunities that these environments offer (Kroski, 2008; Lippincott, 2010; Bell, 2012).

The UDS Library will have to contend with a number of challenges in its quest toward the future implementation of social media and mobile services. There are many challenges inherent to the technological products, for axample: small screens (of mobile phones) can make it difficult to clearly read documents, there is a fairly limited memory of less "smart" devices, and there is the inability of most mobile 
devices to print documents. Others issues can be overcome, such as the lack of adequate Internet access, slow connectivity in general and specifically that of mobile devices in the country, the lack of knowledge and ICT specific skills of the librarians who would implement the technologies, among others.

Based on the findings of the study, the following recommendations for the UDS Library can be made:

- The management of the UDS library system should, as a matter of urgency, initiate some social media-based services.

- The UDS library needs to fully automate its system in order to successfully implement a mobile based library service.

- The management of the University and the ICT department should also seriously consider providing broader Internet bandwidth to the library, so it can support such services.

- With this in mind, the UDS management should also commit a substantial amount of money to ensure the implementation and subsequent sustainability of a project of this nature.

- The library should consider recruiting staff with the required technical expertise.

- Alternatively, identified staff with potential to acquire this necessary technical know-how could also be retrained to adequately manage the project.

- It is also essential that the UDS Library puts in place a continuous training package for its entire staff.

- The library should also offer training to students on how to effectively use social media applications through their mobile devices to access the library's information resources and services.

\section{Conclusion}

Social media applications and mobile technologies have radically changed the way people access and use information. One of the biggest challenges facing an organization is to find ways in which a company can identify the new opportunities enabled by these devices and services (Jones, 2011). This view is underscored by Stephen Bell who posits that academic libraries, rather than trying to guess the future, should be "working to shape (their) vision of a preferred future" for themselves (Bell, 2012).

Many academic libraries all over the world are taking advantage of mobile and social technologies to deliver enhanced services to their users. In African university libraries the development of such services has been slow and unplanned. This can be attributed mainly to the lack of resources, as the costs of technological and communication infrastructure far exceeds budgets allocated for library and other information systems (Makori, 2012). However, this study has clearly shown that there is great potential for the future implementation of these technologies at the University for Development Studies Library in Ghana.

Although this investigation relates specifically to the situation at the University for Development Studies, it could serve not only as foundation for further research and implementation for such services at other universities in the country. Moreover, the 
results and suggestions could also be of value for similar institutions with comparable situations in the rest of Africa and developing countries in other regions.

\section{References}

ACRL (Association of College and Research Libraries) Research Committee (2008) Environmental Scan, 2007. Chicago, Ill.: ACRL.

Alexander B (2008) Social networking in highereducation. In: Katz RN (ed) The Tower and the Cloud: Higher Education in the Age of Cloud Computing. Boulder, CO.: Educause: pp.197-201.

Bell S (2012) The future of academic libraries. Available at: http://www.educationfutures.com/2012/03/26/the-future-of-academic-libraries-an-interviewwith-steven-j-bell/ (accessed 23 September 2012).

Berg B L (1998) Qualitative Research Methods for the Social Sciences (3 ${ }^{\text {rd }}$ ed). Boston, MA.: Allyn \& Bacon.

Cann A, Konstantia D and Hooley T (2011) Social Media: a Guide for Researchers. University of Leicester, Leicester: Research Information Network.

Castells M (2007) Mobile Communication and Society: A Global Perspective. Cambridge, MA.: MIT Press.

Chisenga J (2012) Social media skills and social media strategies important for libraries in Africa. In: SCECSAL Forum: an unofficial blog of the Standing Conference of Eastern, Central and Southern African Library and Information Associations (SCECSAL). Available at: http://scecsal.blogspot.com/2012/06/social-media-skills-and-social-media.html (accessed 26 July 2013).

Choy F (2010) From library stacks to library-in-a-pocket: will users be around? Library Management 32(1/2): 62-72.

Chua A and Goh D (2010) A study of Web 2.0 applications in library websites. Library and Information Science Research 32(3): 203-11.

Farrell MB (2012) Cambridge becoming social media research hub. The Boston Globe, July 28, 2012.

Ghana MMA (2013) Ghana is first in mobile broadband penetration in Africa. Available at: http://www.ghanamma.com/2013/01/ghana-is-first-in-mobile-broadband-penetration-inafrica/ (accessed 15 January 2013).

Harinarayana NS and Raju NV (2010) Web 2.0 features in university library web sites. Electronic Library 28(1): 69 - 88.

Hey J (2007) Designing mobile digital library services for pre-engineering and technology literacy. International Journal of Engineering Education 10(3): 441-453.

Jones N (2011). The Mobile Scenario: Confusion, Complexity and Opportunity through 2015. Stamford, CT.: Gartner. 
Kroski E (2008) On the move with the mobile web: libraries and mobile technologies. Available at: http://eprints.rclis.org/12463/1/mobile_web_ltr.pdf (accessed 20 October 2012).

Lippincott JK (2010) A mobile future for academic libraries. Reference Services Review 38(2): 205-213.

Luo L and Bell L (2010) Text 4 answers: a collaborative service model. Reference Services Review 38(2): 274-283.

Mahmood K and Richardson JV Jr (2011) Adoption of Web 2.0 in US academic libraries: a survey of ARL library websites. Program: Electronic Library and Information Systems 45(4): $365-375$.

Makori EO (2012) Bridging the information gap with the patrons in university libraries in Africa: the case for investments in web 2.0 systems. Library Review, 61(1): 30-40.

Mason R and Rennie F (2008) E-learning and Social Networking Handbook: Resources for Higher Education. New York, N.Y.: Routledge.

Murray L (2010) Libraries "like to move it, move it". Reference Services Review 38(2): 233 249.

Penzhorn C and Pienaar H (2009) The use of social networking tools for innovative service delivery at the University of Pretoria Library. Innovation 38: 66-77.

Powell RR and Connaway LS (2004) Basic Research Methods for Librarians (4 ${ }^{\text {th }}$ ed). Westport, Conn.: Libraries Unlimited.

Sarantakos S (2005) Social Research ( $3^{\text {rd }}$ ed). New York, N.Y.: Palgrave Macmillan.

Simmonds PL (2001) Usage of academic libraries: the role of service quality, resources and user characteristics. Library Trends 49(4): 626-634.

Tess PA (2013) The role of social media in higher education classes (real and virtual): a literature review. Computers in Human Behaviour 29: 60-68.

UNDP (United Nations Development Programme) (2012) Mobile technologies and empowerment: enhancing development through participation and innovation. Executive summary. Available at: www.undpegov.org/mgov-primer.html (accessed 15 July 2012).

Vila MC, Galvez AP and Campos JC (2010) Mobile services in the Rector Gabriel Ferrate Library, Technical University of California. Reference Services Review 38(2): 321-334.

Wentzel P et al (2005) Using Mobile Technology to Enhance Students' Educational Experiences: ECAR Case Study 2.

Available at: http://net.educause.edu/ir/library/pdf/ers0502/cs/ecs0502.pdf (accessed 12 July 2012). 